\title{
Negative Adjectives and Transformation Values
}

\author{
Galit Weidman Sassoon \\ Ben Gurion University of the Negev
}

\section{Introduction}

Consider two birds, an ostrich and a chicken. The height of the former, sixty inches, is twice the height of the latter, as illustrated in Figure 1.

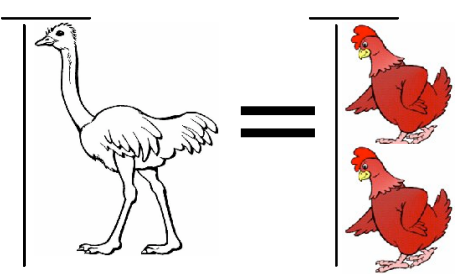

Figure 1: The height of the ostrich is twice the height of the chicken

Here are some well known, yet still puzzling facts.

First, we can felicitously say that the ostrich is sixty inches tall, but we cannot felicitously say that the chicken is thirty inches short. Generally speaking, unlike negative adjectives, positive adjectives license numerical degree modifiers ('measure phrases' like sixty inches). Then again, we could say both that the ostrich is thirty inches taller than the chicken and that the chicken is thirty inches shorter than the ostrich. Thus, in the comparative, both positive and negative-adjectives license numerical degree modifiers (Horn 1972, Seuren 1978, 1984, von Stechow 1984b, Bierwisch 1989, Kennedy 2001). Finally, some positive adjectives resemble negative ones, thus forming an exception to this puzzling generalization. For example, it is somewhat awkward to say that yesterday was thirty degrees warm, though it's perfectly acceptable to say that yesterday was thirty degrees warmer than today (Kennedy 2001). So in terms of the licensing of numerical degree modifiers, warm resembles its negative antonym cold and not other positive adjectives.

Second, cross-polar comparisons like the ostrich is taller than the chicken is short are infelicitous (Kennedy 1999, 2001). ${ }^{1}$ Then again, though

This work was made possible by the Orgler Scholarship for excellent PhD students in the humanities, Tel Aviv University (2004-2007), and the Pratt postdoc scholarship, Ben Gurion University of the Negev (2007-2008). I warmly thank my former supervisors Nirit Kadmon and Fred Landman and the audience of SALT XVIII, Amherst, and the linguistic colloquiums of Jerusalem, Bar-Ilan and Bee'r-Sheva, for their most helpful comments. Special thanks to Arik Cohen, Nomi Shir, Idan Landau, Dorit Ben-Shalom, Lavi Wolf, Rachel Giora, Irene Heim, Chris Kennedy, Yael Sharvit, Jonathan Bobaljik, Gabi Danon, Jonathan Fine, Susan Rothstein, Yael Greenberg, Idit Doron, Anita Mittwoch and Ivy Sichel. I also thank Adar Weidman for encouraging me and for many helpful comments on my papers.

${ }^{1}$ Regarding examples such as my clock is faster than your clock is slow, Kennedy (1999, 2001) convincingly show that these are interpreted as comparisons of deviation from a 
the inverse cross-polar comparison, e.g., the chicken is shorter than the ostrich is tall, is rather odd too, it is marginally accepted when there is no emphatic stress on tall (Landman 2005). Its status further improves when tall is replaced by a different antonym, as in the ladder is shorter than the house is high, or than the gap is narrow (Buring 2006). So we prefer cross-polar comparisons where the negative adjective is in the matrix clause, as opposed to comparisons where it is in the subordinate than-clause. The reasons for this preference are unclear.

Third, though it is perfectly acceptable to say that the ostrich is twice as tall as the chicken, to say that the chicken is twice as short is awkward (Horn 1972, Seuren 1978, 1984, von Stechow 1984b, Bierwisch 1989, Kennedy 2001). The use of ratio statements with negative adjectives is not completely ruled out. Yet, these statements are significantly less felicitous than ratio statements with the corresponding positive antonyms, and they are significantly less often used (for a corpus study supporting this claim see Sassoon 2008a). The felicity contrasts in (1)-(3) further demonstrate this.

a. The table is twice as long as the sofa

b. ?The table is twice as short as the sofa

a. The table is twice as big as the chair

b. ?The table is twice as small as the chair

a. Dan is twice as fast as Sam

b. ?Dan is twice as slow as Sam

This paper attempts to provide an innovative account for these generalizations and for some of their relatively systematic exceptions. Section 2 sets out basic assumptions concerning the analysis of gradable adjectives. First and foremost, I adopt the view that gradable adjectives are linked to measure functions - mapping of entities to degrees. I propose that a highly standard assumption (cf. Klein 1991), namely that the mapping is additive (in the sense defined in Section 2), only holds for positive adjectives, and I describe the type of non-additive mapping functions which, when linked to an adjective, make it negative. Section 3 shows that this proposal directly predicts the differences between positive and negative adjectives.

\section{Positive and Negative Adjectives, My Proposal}

In order to set the stage for my analysis of negative adjectives, I have to employ basic assumptions regarding the representation of partial information and gradability.

\subsection{Representing (Partial) Information}

First, following Stalnaker (1978), let us call the linguistic and world knowledge of a random given community of speakers an actual context. Given a domain of discourse $\mathrm{D}$ and a set of worlds $\mathrm{W}$, let us represent the information in an actual context $\mathrm{c}$ with a subset $\mathrm{W}_{\mathrm{c}}$ of $\mathrm{W}-$ The set of worlds 
which are consistent with the information in c (the worlds that may yet be discovered to be the actual world). For example, the truth of a statement like it rains is considered common knowledge in a given context $\mathrm{c}$ iff it holds true in every world $\mathrm{W}$ in $\mathrm{W}_{\mathrm{c}}$; the falsity of a statement is considered common knowledge in c iff it is false (e.g., it does not rain) in every world $w$ in $\mathrm{W}_{\mathrm{c}}$. The truth value of this statement is unknown or undetermined in $\mathrm{c}$ iff $\mathrm{W}_{\mathrm{c}}$ includes both a world in which it rains and a world in which it does not rain. Generally:

For any statement $\varphi$ :

a. $\llbracket \varphi \rrbracket_{\mathrm{c}}=1$ iff $\forall \mathrm{w} \in \mathrm{W}_{\mathrm{c}}, \llbracket \varphi \rrbracket_{\mathrm{w}}=1$

b. $\llbracket \varphi \rrbracket_{\mathrm{c}}=0$ iff $\forall \mathrm{w} \in \mathrm{W}_{\mathrm{c}}, \llbracket \varphi \rrbracket_{\mathrm{w}}=0$

c. Otherwise, $\llbracket \varphi \rrbracket_{c}$ is unknown (undetermined in c)

\subsection{The Ontology of Degrees}

Since Russell (1905), semanticists often characterize gradable adjectives as mapping entities $\mathrm{d} \in \mathrm{D}$ to degrees. For example, the adjective tall maps entities to degrees representing their heights. Degrees are usually described as elements of a linearly ordered dense set (Kennedy 1999). There is much controversy as to the nature of this dense set of degrees (for a review of different ontologies of degrees, see Klein 1991). In particular, in previous analyses of negative adjectives (such as Seuren 1978, 1984, von Stechow 1984b, Bierwisch 1989, Kennedy 1999, 2001, Schwarzschild 2005; Heim 2000, 2008), gradable adjectives map entities to sets of numbers (to 'intervals' or 'extents'). In these theories, the acceptability of examples like (5) shows that we may truthfully assign to an individual many different degrees.

Sam is as tall as Dan is, and, in fact, taller

Thus, according to these theories gradable adjectives map entities to intervals (sets of degrees).

Conversely, in this paper I will employ the simpler and more intuitive assumption that gradable adjectives map entities to single points, single real numbers $r \in \mathfrak{R}$.

(6) For any world $\mathrm{w}$ of $\mathrm{W}$, and gradable adjective $\mathrm{P}$, let $\mathrm{f}_{\mathrm{P}, \mathrm{w}} \in \mathfrak{R}^{\mathrm{D}}$ be $\mathrm{P}^{\prime} \mathrm{s}$ degree function in w (e.g., $\mathrm{f}_{\text {tall,w }} \in \mathfrak{R}^{\mathrm{D}}$ is tall's degree function in $\mathrm{w}$ ).

My proposal predicts the acceptability of examples like (5) while maintaining that degrees are numbers. In fact, precisely because degrees are numbers, degree denoting expressions (like two meters tall or as tall as Dan is) predictably resemble numerals (expressions like two, three, etc.) in that, depending on various contextual factors, they sometimes have 'at least' readings (Kadmon 1987; e.g., 5). This fact does not justify the use of intervals, which is counter-intuitive and complex (Schwarzschild and Wilkinson 2002). My analysis of negative adjectives can be made compatible with other degree ontologies, and specifically, with interval theories. However, by showing that 
we do not have to add this extra complexity, I provide justification for a more general claim, namely that adjectives do not map entities to intervals at all. ${ }^{2}$

With these basic assumptions set, we can now proceed to describe the notion of additive functions and the role it plays in my account of the differences between positive and negative adjectives.

\subsection{The Quantity Metaphor: Additive Functions}

Comparative morphemes have quantity readings, as in More boys than girls smile, and extent readings, as in Dan is happier than Sam. Semanticists often also describe extent readings in terms of a quantity metaphor. Moltmann (2006) argues that the extent to which entities satisfy an adjective, for instance happy, reflects the quantity that they possess of the thing denoted by the adjective's nominalization, happiness (where one's happiness is an element of the domain D, just like one's legs or hair). Accordingly, when semanticists discuss gradable adjectives, they often assume they are associated with 'ordering-dimensions', e.g. happiness for happy, height for tall, etc. (see Kennedy 1999, Schwarzschild 2006).

Quantity functions are additive (Klein 1991). For example, the number of apples in two baskets together equals the sum of the apples in each separate basket. Accordingly, semantic theories postulate that adjectives' degree functions are additive with respect to their nominalization. Consider for instance, the adjective tall, which can be seen as measuring quantities of height. Klein (1991) symbolizes the concatenation (placing end to end) of two entities $d_{1}$ and $d_{2}$ as $d_{1} \oplus_{\text {height }} d_{2}$. The degree function of tall, $f_{\text {tall }}$, is additive in the sense that it adequately represents the fact that the height of the concatenation of two entities $\left(d_{1} \oplus_{\text {height }} d_{2}\right)$ equals the sum of the heights of the two separate entities $\left(\mathrm{d}_{1}\right.$ and $\left.\mathrm{d}_{2}\right)$. In general, the values of additive functions (with respect to a quality Q) represent the differences and ratios between quantities of $Q$ in entities, as illustrated in (7).

(7) $\forall \mathrm{w} \in \mathrm{W}$, tall's degree function in $\mathrm{w}, \mathrm{f}_{\text {tall, } \mathrm{w}}$, is additive with respect to height:

a. Differences between degrees adequately represent differences between "quantities of height" in entities:

$\mathrm{f}_{\text {tall, w }}\left(\mathrm{d}_{1} \oplus_{\text {height }} \mathrm{d}_{2}\right)=\mathrm{f}_{\text {tall,w }}\left(\mathrm{d}_{1}\right)+\mathrm{f}_{\text {tall,w }}\left(\mathrm{d}_{2}\right)$

b. Ratios between degrees adequately represent ratios between "quantities of height" in entities:

$$
\mathrm{f}_{\text {tall,w }}\left(\mathrm{d}_{1}\right)=\mathrm{f}_{\text {tall,w }}\left(\mathrm{d}_{2}\right) \quad \text { iff } \mathrm{f}_{\text {tall,w }}\left(\mathrm{d}_{1} \oplus_{\text {height }} \mathrm{d}_{2}\right)=2 \times \mathrm{f}_{\text {tall,w }}\left(\mathrm{d}_{1}\right)
$$

In other words, we distinguish between real entities - apples, heights, lengths (the physical objects we measure with a ruler), happiness extents (feelings, internal states) - and numbers. In the same way that the number ' 5 ', can represent the quantity of apples in a basket, it can also represent a given amount of height or happiness. The additivity constraint implies that if two

\footnotetext{
${ }^{2}$ Since Schwarzschild and Wilkinson (2002), intervals are used for various purposes other than analayzing antonymy. These other issues, it seems, can also be dealt with without intervals (for a discussion see Landman 2005, Heim 2006, Sassoon 2007, Gajewsky 2008).
} 
entities are equally tall (have the same amount of height, so to speak), they are mapped to the same number (e.g., 5), and their concatenation is mapped to twice that number (e.g. 10).

Note that many functions (many types of rulers, if you like) adequately represent heights. Any function that maps equally tall entities to the same number and that maps the concatenation of $n$ equally tall entities to $n$ times that number, is additive with respect to height. For example, we have seen that the mapping of two equally tall entities, $\mathrm{d}_{1}$ and $\mathrm{d}_{2}$, and their concatenation, $\mathrm{d}_{1} \oplus_{\text {height }} \mathrm{d}_{2}$, to the values 5,5 and 10 , respectively, conforms to the additivity constraint. But so is their mapping to 2,2, and 4, respectively, and so is their mapping to 100, 100 and 200, respectively, etc. Each mapping corresponds to (the outcome of measuring entities' heights with) some possible ruler (inch, centimeter, meter, etc.)

We see that many different functions may be associated with adjectives like tall in different worlds $\mathrm{w}$ of $\mathrm{W}_{\mathrm{c}}$ of an actual context $\mathrm{c}$. Nevertheless, all these functions adequately represent height ratios (in the sense that they share the same ratios between degrees), e.g., as the height of $\mathrm{d}_{1} \oplus_{\text {height }} \mathrm{d}_{2}$ is twice the height of $d_{1}$, the ratio between their degrees is the number 2 in all the examples just given $(2 \times 5=10 ; 2 \times 2=4$ and $2 \times 100=200)$.

\subsection{Negative Adjectives: Non-additive Functions}

Semanticists often assume that the values assigned to entities by the degree functions of negative adjectives like short, depend on the quantities of height possessed by the entities (Rullmann 1995, Landman 2005) or not possessed by the entities (Seuren 1978, 1984, von Stechow 1984, Kennedy 1999, 2001, Schwarzschild 2005). But is the mapping of entities to degrees in negative adjectives like short additive with respect to these quantities? I submit that it is not. In order to explain this claim, we have to consider the kind of intuitions we do or do not have about the degrees assigned by negative adjectives.

What do we know about short's degree function in actual contexts? We know (we have a very strong intuition) that the entity ordering of short is reversed in comparison with that of tall, based on intuitions such as (8).

Dan is taller than Sam iff Sam is shorter than Dan

I submit that this shows that the degrees (or degree functions) of positive and negative adjectives are reversed. If Dan is mapped to a higher degree in tall Sam is mapped to a higher degree in short. Furthermore, the reversal is linear, in the sense that the differences between degrees are preserved, as demonstrated by the intuitive judgment in (9).

(9) Dan is two inches taller than Sam iff Sam is two inches shorter than Dan

Thus, in every world $\mathrm{w}$ in $\mathrm{W}_{\mathrm{c}}$, the reversal induced by short preserves the difference between entities' degrees. The difference between the degrees $f_{\text {tall,w }}$ assigns to Dan and Sam is two inches in a world w iff the difference between the degrees $f_{\text {short,w }}$ assigns to Dan and Sam is two inches in w). 
What kind of functions are linearly reversed (in the above sense) in comparison with, e.g., $f_{\text {tall,w}}$ ? It is easy to see that by multiplying $f_{\text {tall,w }}$ 's values by -1 they are linearly reversed. Let the function $f_{0 \text {-tall }}$ be such that for any $d$ in $D$ it assigns the value $f_{\text {tall,w }}$ assigns to $d$ multiplied by $-1\left(f_{0-\text { tall }}:=\lambda d .0-\right.$ $\mathrm{f}_{\text {tall,w }}(\mathrm{d})$ ). In order to see that $\mathrm{f}_{0-\text { tall }}$ is linearly reversed in comparison with $\mathrm{f}_{\text {tall,w }}$, consider again two equally tall entities $d_{1}$ and $d_{2}$ whose value in $f_{\text {tall,w }}$ is 5 . By its definition, $\mathrm{f}_{0 \text {-tall }}$ maps both these entities to the value -5 , and it maps their concatenation to the value -10 .
a. $\mathrm{f}_{0 \text {-tall }}\left(\mathrm{d}_{1}\right)=-\mathrm{f}_{\text {tall,w }}\left(\mathrm{d}_{1}\right)=-5$
b. $\mathrm{f}_{0-\text { tall }}\left(\mathrm{d}_{2}\right)=-\mathrm{f}_{\text {tall,w }}\left(\mathrm{d}_{2}\right)=-5$
c. $\mathrm{f}_{0-\text { tall }}\left(\mathrm{d}_{1} \oplus_{\text {height }} \mathrm{d}_{2}\right)=-\mathrm{f}_{\text {tall, }}\left(\mathrm{d}_{1} \oplus_{\text {height }} \mathrm{d}_{2}\right)=-(5+5)=-10$

We see that $\mathrm{f}_{0 \text {-tall }}$ is reversed in comparison with $\mathrm{f}_{\text {tall,w }}$ (while the latter assigns $d_{1} \oplus_{\text {height }} d_{2}$ a bigger degree than the one it assigns to $d_{1}, 10>5$, the former assigns $\mathrm{d}_{1} \oplus_{\text {height }} \mathrm{d}_{2}$ a smaller degree than the one it assigns to $\mathrm{d}_{1},-10<$ $-5)$. Furthermore, $\mathrm{f}_{0 \text {-tall }}$ is linearly reversed in comparison with $\mathrm{f}_{\text {tall,w }}$ as the difference between these two degrees is preserved (the difference between -10 and -5 is still 5 ).

In addition, $\mathrm{f}_{0-\text { tall }}$ conforms to the additivity constraint. It maps any two equally tall entities to the same number (e.g., both $d_{1}$ and $d_{2}$ are mapped to -5) and it maps their concatenation to twice that number $\left(\mathrm{d}_{1} \oplus_{\text {height }} \mathrm{d}_{2}\right.$ is mapped to -10 which is precisely twice -5 ).

However, there are many - in fact, infinitely many - other functions that are linearly reversed in comparison with $\mathrm{f}_{\text {tall,w. }}$. For any real number Tran $\in \mathfrak{R}$, a function $\mathrm{f}_{\text {Tran-tall }}$ that assigns any $d$ the degree $\left(\right.$ Tran $-f_{\text {tall,w }}(d)$ ) linearly reverses the degrees assigned by $f_{\text {tall,w. }}$. Moreover, only when the

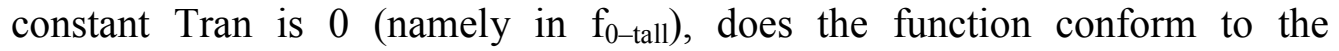
additivity constraint. Transformed functions (whether reversed or not) do not adequately represent differences and ratios between entities' heights. Rather, they transform the additive height values by a constant. To demonstrate this, let us consider some examples of linearly-reversed transformed functions.
a. $\mathrm{f}_{1-\text { tall }}$
$:=$
$\lambda$ d. $1-\mathrm{f}_{\text {tall,w }}(\mathrm{d})$
b. $\mathrm{f}_{2-\text { tall }}$
$\lambda$ d. $2-\mathrm{f}_{\text {tall,w }}(\mathrm{d})$
c. $\mathrm{f}_{3.75-\text { tall }}:=$
$\lambda$ d. $3.75-\mathrm{f}_{\text {tall,w }}(\mathrm{d})$
d. $\mathrm{f}_{-4-\text { tall }}:=$
$\lambda$ d. $-4-\mathrm{f}_{\text {tall,w }}(\mathrm{d})$

The function in (11a), $\mathrm{f}_{1-\text { tall, }}$, maps any $\mathrm{d}$ in $\mathrm{D}$ to the constant 1 minus the value $\mathrm{f}_{\text {tall,w }}$ assigns to $\mathrm{d}$. The zero point is transformed (or displaced) by 1 . The transformation value, 1 , functions as 'the local zero' (or the reference value).
a. $\mathrm{f}_{1-\text { tall }}\left(\mathrm{d}_{1}\right)=1-\mathrm{f}_{\text {tall,w }}\left(\mathrm{d}_{1}\right)=1-5=-4$
b. $\mathrm{f}_{1-\text { tall }}\left(\mathrm{d}_{2}\right)=1-\mathrm{f}_{\text {tall,w }}\left(\mathrm{d}_{2}\right)=1-5=-4$
c. $\mathrm{f}_{1-\text { tall }}\left(\mathrm{d}_{1} \oplus_{\text {height }} \mathrm{d}_{2}\right)=1-\mathrm{f}_{\text {tall,w }}\left(\mathrm{d}_{1} \oplus_{\text {height }} \mathrm{d}_{2}\right)=1-10=-9$

We see that, by its definition, $f_{1-\text { tall }}$ maps $d_{1}$ to -4 and $d_{1} \oplus_{\text {height }} d_{2}$ to -9 . This function is linearly reversed in comparison with $\mathrm{f}_{\text {tall,w }}$ as the difference between these two degrees is preserved (the difference between -9 and -4 is 
still 5). Yet, this function is not additive with respect to height as the ratios between the degrees that this function assigns do not adequately represent the ratios between the quantities of height in entities, e.g., the ratio between the degrees of $d_{1} \oplus d_{2}$ and $d_{1}$ is $9 / 4$ and the ratio between their heights is $8 / 4$.

We see that our intuitions regarding antonym pairs are consistent with the view that negative adjectives are linked to functions that are linearly reversed in comparison with their positive antonyms, as stated in (13).

$$
\forall \mathrm{w} \in \mathrm{W}, \exists \operatorname{Tran} \in \mathfrak{R}, \mathrm{f}_{\text {short,w }}=\mathrm{f}_{\text {Tran-tall }}:=\lambda \mathrm{d} . \text { Tran }-\mathrm{f}_{\text {tall,w }}(\mathrm{d})
$$

But, crucially, our intuitions do not tell us anything else about the degrees assigned by negative adjectives like short. In other words, we know that they are produced by a linearly-reversed function, but we do not know which linearly-reversed function. In particular, I submit that we do not have intuitions that unequivocally tell us that the transformation value of short, $\operatorname{Tran}_{\text {short,w}}$, is 0 , in every world $\mathrm{w}$ in $\mathrm{W}_{\mathrm{c}}$ of any actual context $\mathrm{c}$. Rather, the transformation value is unspecified (it varies across worlds in $\mathrm{W}_{\mathrm{c}}$ of any given c), as stated in (14). In any actual context c:

$$
\neg \exists \operatorname{Tran} \in \mathfrak{R}, \forall \mathrm{w} \in \mathrm{W}_{\mathrm{c}} \mathrm{f}_{\text {short,w }}=\mathrm{f}_{\text {Tran-tall }}:=\lambda \mathrm{d} . \text { Tran }-\mathrm{f}_{\text {tall,w }}(\mathrm{d})
$$

\subsection{Summary}

Let us recapitulate. I propose that the functions associated with positive adjectives like tall are based on conventional, additive, measuring systems (rulers), while the functions of their negative antonyms, e.g. short, are based on function reversal. There are many functions that are linearly reversed in comparison with a given function, $\mathrm{f}_{\text {tall,w }}, \mathrm{e} . \mathrm{g}$., $\mathrm{f}_{0 \text {-tall }}, \mathrm{f}_{1 \text {-tall }}, \mathrm{f}_{2 \text {-tall }}$, etc. Any one of these functions may form the degree function of short. Formally, this means that in every world $\mathrm{w}$ of $\mathrm{W}_{\mathrm{c}}$ (for every actual context $\mathrm{c}$ ), there is a (possibly

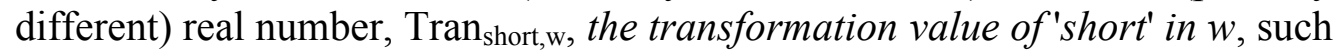
that $\mathrm{f}_{\text {short,w }}(\mathrm{d})=\operatorname{Tran}_{\text {short,w }}-\mathrm{f}_{\text {tall,w }}(\mathrm{d})$. No real number forms the transformation value of short in every $\mathrm{w}$ of $\mathrm{W}_{\mathrm{c}}$ of an actual context $\mathrm{c}$.

In the following, I show that the generalizations reviewed in Section 1, including the existence of systematic exceptions to these generalizations, directly derive from this proposal.

\section{Direct Results}

In order to demonstrate the predictions of my proposal, let us examine the working of a simplified context $\mathrm{c}$, represented by three possible worlds $\left(\mathrm{W}_{\mathrm{c}}=\right.$ $\left.\left\{\mathrm{w}_{1}, \mathrm{w}_{2}, \mathrm{w}_{3}\right\}\right){ }^{3}$ Let the domain of discourse consist of three entities $\left(\mathrm{D}=\left\{\mathrm{d}_{1}\right.\right.$, $\left.\mathrm{d}_{2}, \mathrm{~d}_{3}\right\}$ ), where $\mathrm{d}_{1}$ is one inch tall (an inch 'unit-object'), and $\mathrm{d}_{2}$ and $\mathrm{d}_{3}$ are the ostrich and the chicken as represented in Figure 1, respectively. Table 1 and Table 2 present the facts pertaining to the mapping functions of tall and short respectively, in the given context $\mathrm{c}$.

\footnotetext{
${ }^{3}$ Naturally, every actual context is consistent with many more worlds (but three worlds suffice to demonstrate our main points).
} 
On the one hand, as demonstrated in Table 1, the functions associated with the positive adjective tall in $\mathrm{c}$ are all additive. Their transformation value equals zero (none has a 'transformed local zero', so to speak). Consequently, they all adequately represent (the ratios and differences between) entities' heights. For example, the fact that in c we can tell that the height of the ostrich, $d_{2}$, is twice the height of the chicken, $d_{3}$, and sixty times the height of the inch, $d_{1}$, is represented by the fact that in every $\mathrm{w}$ of $\mathrm{W}_{\mathrm{c}}, \mathrm{f}_{\text {tall,w }}\left(\mathrm{d}_{2}\right)$ (the value tall assigns to the ostrich) is twice $\mathrm{f}_{\text {tall,w }}\left(\mathrm{d}_{3}\right)$ (the value tall assigns to the chicken), and sixty times $\mathrm{f}_{\text {tall,w }}\left(\mathrm{d}_{1}\right)$ (the value tall assigns to the inch). For example, in $\mathrm{w}_{1}, \mathrm{f}_{\text {tall,wl }}\left(\mathrm{d}_{2}\right)=60=2 \times \mathrm{f}_{\text {tall, } \mathrm{w} 1}\left(\mathrm{~d}_{3}\right)=2 \times 30=60 \times \mathrm{f}_{\text {tall,w1 }}\left(\mathrm{d}_{1}\right)=60 \times 1$.

TABLE 1: The functions linked to tall in $\mathrm{c}$ are based on additive measuring systems (possible rulers)

\begin{tabular}{ccccc}
\hline $\mathbf{f}_{\text {tall,w }}$ & $\begin{array}{c}\text { The } \\
\text { transformation } \\
\text { value of } \text { tall } \text { in } \mathbf{w} \\
\text { Tran }_{\text {tall,w }}\end{array}$ & $\begin{array}{c}\text { An inch } \\
\text { unit-object } \\
\mathbf{d}_{\mathbf{1}}\end{array}$ & $\begin{array}{c}\text { The ostrich } \\
\text { of Figure 1 } \\
\mathbf{d}_{\mathbf{2}}\end{array}$ & $\begin{array}{c}\text { The chicken } \\
\text { of Figure 1 } \\
\mathbf{d}_{\mathbf{3}}\end{array}$ \\
\hline $\mathrm{W}_{1}$ & $\mathbf{0}$ & 1 & 60 & 30 \\
\hline $\mathrm{W}_{2}$ & $\mathbf{0}$ & 2 & 120 & 60 \\
\hline $\mathrm{W}_{3}$ & $\mathbf{0}$ & 3 & 180 & 90 \\
\hline
\end{tabular}

On the other hand, as demonstrated in Table 2, the functions associated with the negative adjective short in c are not all additive. They are based on function reversal. We can tell that short's functions are linearly reversed compared with tall's functions, but we cannot tell to what extent they are transformed. Formally, if in some world $\mathrm{w}$ of $\mathrm{W}_{\mathrm{c}}$, tall maps an entity $\mathrm{d}$ to $\mathrm{n}$ $\left(\mathrm{f}_{\text {tall,w }}(\mathrm{d})=\mathrm{n}\right)$, short maps $\mathrm{d}$ to $\operatorname{Tran}_{\text {short,w}}-\mathrm{n}\left(\mathrm{f}_{\text {short,w}}(\mathrm{d})=\operatorname{Tran}_{\text {short,w }}-\mathrm{n}\right)$. The value Tran $_{\text {short }}$ is unknown (varies in $\mathrm{W}_{\mathrm{c}}$ ). In some worlds, then, the reversed degrees are transformed by a non-zero constant and, consequently, fail to represent (the ratios and differences between) entities' heights. For example, in $\mathrm{w}_{1}$ the ratios between the heights of the ostrich and the chicken are not adequately represented. As the transformation value of short' in $\mathrm{w}_{1}$, $\operatorname{Tran}_{\text {short,w1 }}$, is 10, short assigns the ostrich in $\mathrm{w}_{1}$ the degree $10-\mathrm{f}_{\text {tall,w1 }}\left(\mathrm{d}_{2}\right)=10$ $-60=-50$, which is not two times the degree short assigns to the chicken in $\mathrm{w}_{1}$, namely the degree $10-\mathrm{f}_{\text {tall,wl }}\left(\mathrm{d}_{3}\right)=10-30=-20$.

TABLE 2: The functions associated with short in c are based on functionreversal: $\forall \mathrm{w} \in \mathrm{W}_{\mathrm{c}}, \mathbf{f}_{\text {short,w }}=\operatorname{Tran}_{\text {short,w }}-\mathbf{f}_{\text {tall,w }}$

\begin{tabular}{ccccc}
\hline $\mathbf{f}_{\text {short,w }}$ & $\begin{array}{c}\text { The } \\
\text { transformation } \\
\text { value of short in } \\
\text { w, Tran }\end{array}$ & $\begin{array}{c}\text { An inch unit- } \\
\text { object } \\
\mathbf{d}_{\mathbf{1}}\end{array}$ & $\begin{array}{c}\text { The ostrich } \\
\mathbf{d}_{\mathbf{2}}\end{array}$ & $\begin{array}{c}\text { The chicken } \\
\mathbf{d}_{\mathbf{3}}\end{array}$ \\
\hline $\mathrm{W}_{1}$ & $\mathbf{1 0}$ & $10-1=$ & $10-60=$ & \\
\hline $\mathrm{W}_{2}$ & $\mathbf{0}$ & $\mathbf{9}$ & $-\mathbf{5 0}$ & $10-30=$ \\
& & $0-2=$ & $0-120=$ & $0-60=$ \\
\hline $\mathrm{W}_{3}$ & $\mathbf{- 1 0}$ & $-\mathbf{2 0}$ & $-\mathbf{1 2 0}$ & $-\mathbf{6 0}$ \\
\hline & & $-10-3=$ & $-10-180=$ & $-10-90=$ \\
& $-\mathbf{1 3}$ & $-\mathbf{1 9 0}$ & $-\mathbf{1 0 0}$ \\
\hline
\end{tabular}


I will first demonstrate how the generalizations concerning the differences between positive and negative adjectives are accounted for, and then attempt to explain their exceptions.

\subsection{Ratio Modifiers}

First, the proposal that the degree functions of negative adjectives are transformed by an unspecified constant directly predicts the fact that negative adjectives like short tend not to combine with ratio modifiers like twice.

In order to see this, let us first focus on tall. Recall that the ostrich has a double height compared with the chicken in c. The degree function of tall adequately represents this fact given that in every world $\mathrm{w}$ in $\mathrm{W}_{\mathrm{c}}$, tall maps the chicken to some number $\mathrm{n}$, and the ostrich to twice that number, $2 \mathrm{n}$ :
a. $\mathrm{f}_{\text {tall,wl }}\left(\mathrm{d}_{2}\right)=\mathbf{6 0}$
$\mathrm{f}_{\text {tall,wl }}\left(\mathrm{d}_{3}\right)=\mathbf{3 0} \Rightarrow \mathrm{f}_{\text {tall,wl }}\left(\mathrm{d}_{2}\right)=2 \times \mathrm{f}_{\text {tall,wl }}\left(\mathrm{d}_{3}\right)$
b. $\mathrm{f}_{\text {tall,w2 }}\left(\mathrm{d}_{2}\right)=\mathbf{1 2 0}$
$\mathrm{f}_{\text {tall,w2 }}\left(\mathrm{d}_{3}\right)=\mathbf{6 0} \Rightarrow \mathrm{f}_{\text {tall,w2 }}\left(\mathrm{d}_{2}\right)=2 \times \mathrm{f}_{\text {tall,w2 }}\left(\mathrm{d}_{3}\right)$
c. $\mathrm{f}_{\text {tall,w3 }}\left(\mathrm{d}_{2}\right)=\mathbf{1 8 0}$
$\mathrm{f}_{\text {tall,w3 }}\left(\mathrm{d}_{3}\right)=\mathbf{9 0} \Rightarrow \mathrm{f}_{\text {tall,w3 }}\left(\mathrm{d}_{2}\right)=2 \times \mathrm{f}_{\text {tall,w3 }}\left(\mathrm{d}_{3}\right)$

As it holds true in any world $\mathrm{w}$ that the ostrich's degree equals twice the chicken's in $\mathrm{w}$, the statement The ostrich is twice as tall as the chicken is true in $\mathrm{c}$.

$$
\begin{aligned}
& \llbracket \text { The ostrich is twice as tall as the chicken } \rrbracket_{\mathrm{c}}=1 \text { iff } \\
& \forall \mathrm{w} \in \mathrm{W}_{\mathrm{c}}, \llbracket \text { The ostrich is twice as tall as the chicken } \rrbracket_{\mathrm{w}}=1 \text { iff } \\
& \forall \mathrm{w} \in \mathrm{W}_{\mathrm{c}}, \mathrm{f}_{\mathrm{tall}, \mathrm{w}}\left(\llbracket \text { The ostrich } \rrbracket_{\mathrm{w}}\right)=2 \times \mathrm{f}_{\mathrm{tall}, \mathrm{w}}\left(\llbracket \text { The chicken } \rrbracket_{\mathrm{w}}\right) \text { iff } \\
& \forall \mathrm{w} \in \mathrm{W}_{\mathrm{c}}, \mathrm{f}_{\mathrm{tall}, \mathrm{w}}\left(\mathrm{d}_{2}\right)=2 \times \mathrm{f}_{\mathrm{tall}, \mathrm{w}}\left(\mathrm{d}_{3}\right)
\end{aligned}
$$

The situation differs with regard to the negative adjective short, whose degree function is reversed and transformed by a value that is unspecified in c. In every $\mathrm{w}$ in $\mathrm{W}_{\mathrm{c}}$, such that tall maps the chicken to $\mathrm{n}$ and the ostrich to $2 \mathrm{n}$ in $\mathrm{w}$, short maps the chicken to $\operatorname{Tran}_{\mathrm{short}, \mathrm{w}}-\mathrm{n}$, and the ostrich to $\operatorname{Tran}_{\mathrm{short}, \mathrm{w}}-2 \mathrm{n}$. But none of these two degrees, $\operatorname{Tran}_{\text {short,w }}-n$ and $\operatorname{Tran}_{\text {short,w }}-2 n$, is twice the other, unless $\operatorname{Tran}_{\text {short,w}}=0$.
a. $\mathrm{f}_{\text {short,wl }}\left(\mathrm{d}_{2}\right)=\operatorname{Tran}_{\text {short,w1 }}-\mathrm{f}_{\text {tall,wl }}\left(\mathrm{d}_{2}\right)=10-60=\mathbf{5 0}$
$\mathrm{f}_{\text {short }, \mathrm{w} 1}\left(\mathrm{~d}_{3}\right)=\operatorname{Tran}_{\text {short,w1}}-\mathrm{f}_{\text {tall,w1 }}\left(\mathrm{d}_{3}\right)=10-30=\mathbf{- 2 0}$
$\mathrm{f}_{\text {tall,w1 }}\left(\mathrm{d}_{2}\right) \neq 2 \times \quad \mathrm{f}_{\text {tall,w1 }}\left(\mathrm{d}_{3}\right)$
b. $\mathrm{f}_{\text {short }, \mathrm{w} 2}\left(\mathrm{~d}_{2}\right)=\operatorname{Tran}_{\text {short, } \mathrm{w} 2}-\mathrm{f}_{\text {tall, } \mathrm{w} 2}\left(\mathrm{~d}_{2}\right)=0-120=\mathbf{- 1 2 0}$
$\mathrm{f}_{\text {short, } \mathrm{w} 2}\left(\mathrm{~d}_{3}\right)=\operatorname{Tran}_{\text {short,w2}}-\mathrm{f}_{\text {tall,w2 } 2}\left(\mathrm{~d}_{3}\right)=0-60=-\mathbf{6 0}$
$\mathrm{f}_{\text {tall,w2 }}\left(\mathrm{d}_{2}\right)=2 \times \quad \mathrm{f}_{\text {tall,w2 }}\left(\mathrm{d}_{3}\right)$
c. $\mathrm{f}_{\text {short,w3 }}\left(\mathrm{d}_{2}\right)=\operatorname{Tran}_{\text {short,w3 }}-\mathrm{f}_{\text {tall,w3 }}\left(\mathrm{d}_{2}\right)=-10-180=-\mathbf{1 9 0}$
$\mathrm{f}_{\text {short }, \mathrm{w} 3}\left(\mathrm{~d}_{3}\right)=\operatorname{Tran}_{\text {short }, \mathrm{w} 3}-\mathrm{f}_{\text {tall, } \mathrm{w} 3}\left(\mathrm{~d}_{3}\right)=-10-90=\mathbf{- 1 0 0}$
$\mathrm{f}_{\text {tall,w3 }}\left(\mathrm{d}_{2}\right) \neq 2 \times \quad \mathrm{f}_{\text {tall,w3 }}\left(\mathrm{d}_{3}\right)$

As it is not the case that in every world $\mathrm{w}$ the ostrich's degree in short equals twice the chicken's in $\mathrm{w}$ (e.g., in $\mathrm{w}_{1}$ and $\mathrm{w}_{3}$ is doesn't), the statement The ostrich is twice as short as the chicken is not true in c. 


$$
\begin{aligned}
& \llbracket \text { The ostrich is twice as short as the chicken } \rrbracket_{\mathrm{c}}=1 \text { iff } \\
& \forall \mathrm{w} \in \mathrm{W}_{\mathrm{c}} \text {, 【The ostrich is twice as short as the chicken } \rrbracket_{\mathrm{w}}=1 \quad \text { iff } \\
& \forall \mathrm{w} \in \mathrm{W}_{\mathrm{c}}, \mathrm{f}_{\text {short, } \mathrm{w}}\left(\llbracket \text { The ostrich } \rrbracket_{\mathrm{w}}\right)=2 \times \mathrm{f}_{\text {short, } \mathrm{w}}\left(\llbracket \text { The chicken } \rrbracket_{\mathrm{w}}\right) \quad \text { iff } \\
& \forall \mathrm{w} \in \mathrm{W}_{\mathrm{c}}, \operatorname{Tran}_{\text {short,w }}-\mathrm{f}_{\text {tall, } \mathrm{w}}\left(\llbracket \text { The ostrich } \rrbracket_{\mathrm{w}}\right)= \\
& 2 \times\left(\operatorname{Tran}_{\text {short,w }}-\mathrm{f}_{\text {tall,w }}\left(\llbracket \text { The chicken } \rrbracket_{\mathrm{w}}\right)\right) \quad \text { iff } \\
& \forall \mathrm{w} \in \mathrm{W}_{\mathrm{c}}, \operatorname{Tran}_{\text {short,w }}-\mathrm{f}_{\text {tall,w }}\left(\mathrm{d}_{2}\right)=2 \times \operatorname{Tran}_{\text {short,w }}-2 \times \mathrm{f}_{\text {tall,w }}\left(\mathrm{d}_{3}\right) \quad \text { iff } \\
& \forall \mathrm{w} \in \mathrm{W}_{\mathrm{c}}, 2 \times \mathrm{f}_{\text {tall,w }}\left(\mathrm{d}_{3}\right)-\mathrm{f}_{\text {tall,w }}\left(\mathrm{d}_{2}\right)=\operatorname{Tran}_{\text {short, }}
\end{aligned}
$$

As it is not the case that in every world w the ostrich's degree in short does not equal two times the chicken's in w (e.g., in $\mathrm{w}_{3}$ it does), the statement The ostrich is twice as short as the chicken is not false in c.

$$
\begin{aligned}
& \llbracket \text { The ostrich is twice as short as the chicken } \rrbracket_{\mathrm{c}}=0 \text { iff } \\
& \forall \mathrm{w} \in \mathrm{W}_{\mathrm{c}}, \llbracket \text { The ostrich is twice as short as the chicken } \rrbracket_{\mathrm{w}}=0 \text { iff } \\
& \forall \mathrm{w} \in \mathrm{W}_{\mathrm{c}}, \mathrm{f}_{\text {short, } \mathrm{w}}\left(\llbracket \text { The ostrich } \rrbracket_{\mathrm{w}}\right) \neq 2 \times \mathrm{f}_{\text {short, } \mathrm{w}}\left(\llbracket \text { The chicken } \rrbracket_{\mathrm{w}}\right) \text { iff } \\
& \forall \mathrm{w} \in \mathrm{W}_{\mathrm{c}}, 2 \times \mathrm{f}_{\mathrm{tall}, \mathrm{w}}\left(\mathrm{d}_{3}\right)-\mathrm{f}_{\mathrm{tall}, \mathrm{w}}\left(\mathrm{d}_{2}\right) \neq \operatorname{Tran}_{\text {short, }}
\end{aligned}
$$

We see that ratio statements with negative adjectives can be neither verified nor falsified in c. In fact, in both their truth conditions and their falsity conditions (18-19, respectively), a meta-language variable occurs, Tran short, $_{\text {, }}$ whose value is unspecified in c (it varies across worlds in $\mathrm{W}_{\mathrm{c}}$ ), rendering the truth value of such statements inherently undetermined (it cannot be known). As this is the situation in every actual context $\mathrm{c}$ where negative adjectives like short receive their default (reversed and transformed) interpretation, ratio statements are by default uninterpretable with negative adjectives.

\subsection{Indeterminacy concerning the Numerical Degrees in Negative Adjectives}

Second, the proposal that the degree functions of negative adjectives are transformed by an unspecified constant directly predicts the indeterminacy concerning the degrees short assigns, and as its direct consequence, the fact that negative adjectives like short cannot felicitously combine with numerical degree modifiers.

I take the denotation of a singular unit noun (e.g., meter) to be a function from an adjective (like tall, wide, long, etc.) to (the characteristic function of) a set of unit objects, e.g., the entities whose height we call 'one meter' (the original meter, any meter ruler, and so on). I take the denotation of a plural unit noun (e.g., meters) in statements like Dan is two meters tall to be (the Schonfinkelized function of) the relation between adjectives $\mathrm{P}$, numbers $\mathrm{n}$, and entities d in D, such that d's amount of P-hood (e.g., d's height) equals $\mathrm{n}$ times that of a meter unit-object, as demonstrated in $(20) .{ }^{4}$

$\llbracket$ Dan is $n$ inches tall $\rrbracket_{\mathrm{w}}=1 \quad$ iff $\mathrm{f}_{\text {tall,w }}(\mathrm{d})=\mathrm{n} \times \mathrm{r}_{\mathrm{i}, \mathrm{w}}$

(where $r_{i, w}$ is the real number $f_{\text {tall,w }}$ assigns to the inch unit-objects).

\footnotetext{
${ }^{4}$ This analysis of unit names is directly based on measurement theory (Krantz et al 1971, Klein 1991). A proper justification for this analysis lies far beyond the scope of this paper (see Sassoon 2007, 2008b). Other analyses of unit names may well be compatible with the analysis of negative adjectives I pursue (Schwarzschild 2006, Brasoveanu 2008, Svenonious and Kennedy 2006). For similar 'relational' interpretations see Krifka (1989) and Chierchia (1998).
} 
This analysis of unit names presupposes that their semantics involves the application of a ratio operation, e.g. the interpretation of Dan is $n$ inches tall boils down to "Dan is n times taller than an inch unit object". Based on this, I propose that the distribution of unit names is restricted to adjectives whose degree functions adequately represent ratios between quantities of the 'stuff' they measure (additive functions). This means that unit names do not combine with transformed adjectives, rendering combinations like 2 inches short uninterpretable. Unit names do combine with adjectives whose degree functions are additive, like tall, rendering combinations like 2 inches (tall) perfectly interpretable (whether the predicative argument tall is explicitly mentioned or not).

Let us first focus on tall. Recall that the ostrich has sixty times the height of the inch in c. Tall's degree function adequately represents this fact:
a. $\mathrm{f}_{\text {tall,w1 } 1}\left(\mathrm{~d}_{2}\right)=\mathbf{6 0}$
$\mathrm{f}_{\text {tall,w1 }}\left(\mathrm{d}_{1}\right)=\mathbf{1} \Rightarrow \mathrm{f}_{\text {tall,w1 }}\left(\mathrm{d}_{2}\right)=60 \times \mathrm{f}_{\text {tall,w1 }}\left(\mathrm{d}_{1}\right)$
b. $\mathrm{f}_{\text {tall,w2 } 2}\left(\mathrm{~d}_{2}\right)=\mathbf{1 2 0}$
$\mathrm{f}_{\text {tall,w2 }}\left(\mathrm{d}_{1}\right)=\mathbf{2} \Rightarrow \mathrm{f}_{\text {tall,w2 }}\left(\mathrm{d}_{2}\right)=60 \times \mathrm{f}_{\text {tall,w2 }}\left(\mathrm{d}_{1}\right)$
c. $\mathrm{f}_{\text {tall,w3 }}\left(\mathrm{d}_{2}\right)=\mathbf{1 8 0}$
$f_{\text {tall,w3 }}\left(d_{1}\right)=\mathbf{3} \Rightarrow f_{\text {tall,w3 }}\left(d_{2}\right)=60 \times f_{\text {tall,w3 }}\left(d_{1}\right)$

As it holds true in any given world $w$ that the ostrich's degree equals sixty times the degree of the inch unit-object in $\mathrm{w}$, the statement The ostrich is sixty inches tall is true in $\mathrm{c}$ :

$$
\begin{aligned}
& \llbracket \text { The ostrich is sixty inches tall } \rrbracket_{\mathrm{c}}=1 \text { iff } \\
& \forall \mathrm{w} \in \mathrm{W}_{\mathrm{c}}, \llbracket \text { The ostrich is is sixty inches tall } \rrbracket_{\mathrm{w}}=1 \text { iff } \\
& \forall \mathrm{w} \in \mathrm{W}_{\mathrm{c}}, \mathrm{f}_{\mathrm{tall}, \mathrm{w}}\left(\llbracket \text { The ostrich } \rrbracket_{\mathrm{w}}\right)=60 \times \mathrm{r}_{\mathrm{i}, \mathrm{w}} \\
& \text { (s.t. } \mathrm{r}_{\mathrm{i}, \mathrm{w}} \text { is the real number } \mathrm{f}_{\mathrm{tall}, \mathrm{w}} \text { assigns to the inch unit-objects) iff } \\
& \forall \mathrm{w} \in \mathrm{W}_{\mathrm{c}}, \mathrm{f}_{\mathrm{tall}, \mathrm{w}}\left(\mathrm{d}_{2}\right)=60 \times \mathrm{f}_{\mathrm{tall}, \mathrm{w}}\left(\mathrm{d}_{1}\right)
\end{aligned}
$$

The situation is different with the negative adjective short, whose degree function is reversed and transformed by a value that is unspecified in c. In every $\mathrm{w}$ in $\mathrm{W}_{\mathrm{c}}$, such that tall maps the inch unit-object to $\mathrm{n}$ and the ostrich to 60n in w, short maps the inch unit-object to $\operatorname{Tran}_{\text {short,w }}-\mathrm{n}$, and the ostrich to $\operatorname{Tran}_{\text {short,w }}-60 \mathrm{n}$. But none of these two degrees, $\mathrm{n}$ and $\operatorname{Tran}_{\text {short,w }}-60 \mathrm{n}$, is sixty times the other, unless $\operatorname{Tran}_{\text {short, } \mathrm{w}}=0$.

$$
\begin{aligned}
& \text { a. } \mathrm{f}_{\text {short }, \mathrm{w} 1}\left(\mathrm{~d}_{2}\right)=\operatorname{Tran}_{\text {short }, \mathrm{w} 1}-\mathrm{f}_{\text {tall, } \mathrm{w} 1}\left(\mathrm{~d}_{2}\right)=10-60=\mathbf{5 0} \\
& \mathrm{f}_{\text {short }, \mathrm{wl} 1}\left(\mathrm{~d}_{1}\right)=\operatorname{Tran}_{\text {short,w1 }}-\mathrm{f}_{\text {tall,w1 }}\left(\mathrm{d}_{1}\right)=10-1 \quad=\mathbf{9} \quad \Rightarrow \\
& \mathrm{f}_{\text {short,wl }}\left(\mathrm{d}_{2}\right) \neq 60 \times \mathrm{f}_{\text {tall,wl }}\left(\mathrm{d}_{1}\right) \\
& \text { b. } \mathrm{f}_{\text {short }, \mathrm{w} 2}\left(\mathrm{~d}_{2}\right)=\operatorname{Tran}_{\text {short }, \mathrm{w} 2}-\mathrm{f}_{\text {tall, } \mathrm{w} 2}\left(\mathrm{~d}_{2}\right)=0-120=\mathbf{- 1 2 0} \\
& \mathrm{f}_{\text {short,w2 }}\left(\mathrm{d}_{1}\right)=\operatorname{Tran}_{\text {short,w2 }}-\mathrm{f}_{\text {tall,w2 }}\left(\mathrm{d}_{1}\right)=0-2 \quad=-\mathbf{2} \Rightarrow \\
& \mathrm{f}_{\text {short,w2 } 2}\left(\mathrm{~d}_{2}\right)=60 \times \mathrm{f}_{\text {tall,w2 } 2}\left(\mathrm{~d}_{1}\right) \\
& \text { c. } \mathrm{f}_{\text {short, } \mathrm{w} 3}\left(\mathrm{~d}_{2}\right)=\operatorname{Tran}_{\text {short }, \mathrm{w} 3}-\mathrm{f}_{\text {tall,w3 }}\left(\mathrm{d}_{2}\right)=-10-180=-\mathbf{1 9 0} \\
& \mathrm{f}_{\text {short }, \mathrm{w} 3}\left(\mathrm{~d}_{1}\right)=\operatorname{Tran}_{\text {short,w3 }}-\mathrm{f}_{\text {tall,w3 }}\left(\mathrm{d}_{1}\right)=-10-3=-\mathbf{1 3} \Rightarrow \\
& \mathrm{f}_{\text {short,w3 }}\left(\mathrm{d}_{2}\right) \neq 60 \times \mathrm{f}_{\text {tall,w3 }}\left(\mathrm{d}_{1}\right)
\end{aligned}
$$

As it is not the case that in every world $\mathrm{w}$ the ostrich's degree in short equals sixty times the inch unit-object's degree in short in $\mathrm{w}, \mathrm{r}_{\mathrm{i}, \mathrm{w}}\left(\mathrm{e} . \mathrm{g}\right.$., in $\mathrm{w}_{1}$ and $\mathrm{w}_{3}$ is doesn't), the statement The ostrich is sixty inches short is not true in c. 
$\llbracket$ The ostrich is sixty inches short $\rrbracket_{\mathrm{c}}=1$ iff

$\forall \mathrm{w} \in \mathrm{W}_{\mathrm{c}}$, , The ostrich is sixty inches short $\rrbracket_{\mathrm{w}}=1 \quad$ iff

$\forall \mathrm{w} \in \mathrm{W}_{\mathrm{c}}, \mathrm{f}_{\text {short, } \mathrm{w}}\left(\llbracket\right.$ The ostrich $\left.\rrbracket_{\mathrm{w}}\right)=60 \times \mathrm{r}_{\mathrm{i}, \mathrm{w}}$

(s.t. $\mathrm{r}_{\mathrm{i}, \mathrm{w}}$ is the real number $\mathrm{f}_{\text {short,w }}$ assigns to the inch unit-objects) iff

$\forall \mathrm{w} \in \mathrm{W}_{\mathrm{c}}, \operatorname{Tran}_{\text {short,w }}-\mathrm{f}_{\text {tall,w }}\left(\mathrm{d}_{2}\right)=60 \times\left(\operatorname{Tran}_{\text {short,w }}-\mathrm{f}_{\text {tall,w }}\left(\mathrm{d}_{1}\right)\right)$ iff

$\forall \mathrm{w} \in \mathrm{W}_{\mathrm{c}}, 60 \times \mathrm{f}_{\text {tall, }}\left(\mathrm{d}_{1}\right)-\mathrm{f}_{\text {tall, }}\left(\mathrm{d}_{2}\right)=59 \times \operatorname{Tran}_{\text {short }, \mathrm{w}}$

As it is not the case that in every world $\mathrm{w}$ the ostrich's degree in short does not equal sixty times the inch unit-object's degree in short in w (e.g., in $\mathrm{w}_{2}$ it does), the statement The ostrich is sixty inches short is not false in c.

$$
\begin{aligned}
& \llbracket \text { The ostrich is sixty inches short } \rrbracket_{\mathrm{c}}=0 \text { iff } \\
& \forall \mathrm{w} \in \mathrm{W}_{\mathrm{c}}, \llbracket \text { The ostrich is sixty inches short } \rrbracket_{\mathrm{w}}=0 \quad \text { iff } \\
& \forall \mathrm{w} \in \mathrm{W}_{\mathrm{c}}, 60 \times \mathrm{f}_{\mathrm{tall}, \mathrm{w}}\left(\mathrm{d}_{1}\right)-\mathrm{f}_{\mathrm{tall}, \mathrm{w}}\left(\mathrm{d}_{2}\right) \neq 59 \times \operatorname{Tran}_{\text {short,w }}
\end{aligned}
$$

Again, in both the truth conditions and the falsity conditions (24-25,

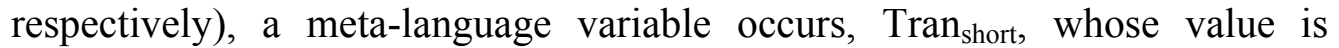
unspecified in $\mathrm{c}$ (it varies across worlds in $\mathrm{W}_{\mathrm{c}}$ ), rendering the truth value of such statements inherently undetermined (it cannot be known). As this is the situation in every actual context $\mathrm{c}$ in which negative adjectives like short receive their default (reversed and transformed) interpretation, combinations of numerical degree modifiers with negative adjectives are ungrammatical.

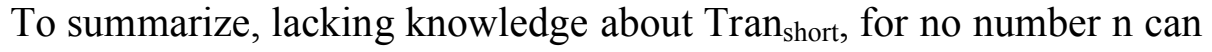
we say which entities are $n$ inches short in $\mathrm{c}\left(\neg \exists \mathrm{d} \in \mathrm{D}\right.$ : $\left.\forall \mathrm{w} \in \mathrm{W}_{\mathrm{c}}, \mathrm{f}_{\text {short,w }}(\mathrm{d})=\mathrm{n}\right)$. So numerical-degree phrases like two inches cannot be used with short. I therefore take it that unit names whose predicative argument is left implicit are automatically interpreted as taking an additive (non-transformed) adjective as an argument, e.g., utterances such as 'two inches' are understood as meaning two inches tall, two inches wide, or two inches long, but not two inches short or two inches narrow. In statements like, e.g., the ostrich is sixty inches short, the predicative argument of inches is specified as short. Therefore, we cannot possibly interpret inches as equivalent to inches tall or inches wide. Consequently, the statement is uninterpretable (infelicitous). ${ }^{5}$

\subsection{Numerical Degree Modifiers in Comparison Statements}

Third, the present proposal correctly predicts that the combination of comparative adjectives such as taller and shorter with numerical degree adjectives such as two inches (tall) should be perfectly interpretable.

I adopt the common view that comparative adjectives express degree differences ${ }^{6}$. For example, comparison statements like The ostrich is taller than the chicken (is) hold true in a given world $\mathrm{w}$ iff the difference between the degrees of the chicken and the ostrich in $\mathrm{w}$ is a positive real number:

\footnotetext{
${ }^{5}$ Though even if we could interpret it as meaning inches tall, the resulting statement, e.g. the ostrich is sixty inches-tall short, is trivially false in c. In every $\mathrm{w}$ in $\mathrm{W}_{\mathrm{c}}$, such that tall maps the inch unit-object to $\mathrm{n}$ and the ostrich to $60 \mathrm{n}$ in w, short maps the ostrich to $\operatorname{Tran}_{\text {short,w }}-60 \mathrm{n}$, which is not 60 times n, even when $\operatorname{Tran}_{\text {short,w }}=0$.

${ }^{6}$ von Stechow (1984), Schwarzschild and Wilkinson (2002), Schwarzschild (2005), Kennedy and McCnally (2005), Kennedy and Levin (2007: 17).
} 
The present analysis predicts that derived comparatives of negative adjectives license numerical degree modifiers (as in The chicken is thirty inches shorter than the ostrich) by virtue of the fact that when degree-differences are computed, the transformation values of the two degrees cancel one another. ${ }^{7}$ Again, let us focus on tall first. The difference between the height of the ostrich and the height of the chicken equals exactly thirty times the height of an inch unit object. The degree function of tall adequately represents this fact given that in every world $\mathrm{w}$ in $\mathrm{W}_{\mathrm{c}}$, the difference between the two degrees tall assigns to the ostrich and the chicken equals exactly thirty times the value tall assigns to an inch unit object (cf. 27). In consequence, the statement The ostrich is thirty inches taller than the chicken is true in c (cf. 28).
a. $\mathrm{f}_{\text {tall,w1 }}\left(\mathrm{d}_{2}\right)-\mathrm{f}_{\text {tall,w1 }}\left(\mathrm{d}_{3}\right)=60-30=\mathbf{3 0}$
$\mathrm{f}_{\text {tall,wl }}\left(\mathrm{d}_{1}\right)=\mathbf{1}$
$\mathrm{f}_{\text {tall,wl }}\left(\mathrm{d}_{2}\right)-\mathrm{f}_{\text {tall,w1 }}\left(\mathrm{d}_{3}\right)=30 \times \mathrm{f}_{\text {tall,wl }}\left(\mathrm{d}_{1}\right)$
b. $\mathrm{f}_{\text {tall, } \mathrm{w} 2}\left(\mathrm{~d}_{2}\right)-\mathrm{f}_{\text {tall,w2 }}\left(\mathrm{d}_{3}\right)=120-60=\mathbf{6 0}$
$\mathrm{f}_{\text {tall,w2 }}\left(\mathrm{d}_{1}\right)=\mathbf{2} \quad \Rightarrow$
$\mathrm{f}_{\text {tall,w2 } 2}\left(\mathrm{~d}_{2}\right)-\mathrm{f}_{\text {tall,w2 }}\left(\mathrm{d}_{3}\right)=30 \times \mathrm{f}_{\text {tall,w2 }}\left(\mathrm{d}_{1}\right)$
c. $\mathrm{f}_{\text {tall,w3 }}\left(\mathrm{d}_{2}\right)-\mathrm{f}_{\text {tall,w3 }}\left(\mathrm{d}_{3}\right)=180-90=\mathbf{9 0} \quad \mathrm{f}_{\text {tall,w3 }}\left(\mathrm{d}_{1}\right)=\mathbf{3} \quad \Rightarrow$ $\mathrm{f}_{\text {tall, } \mathrm{w} 3}\left(\mathrm{~d}_{2}\right)-\mathrm{f}_{\text {tall,w3 }}\left(\mathrm{d}_{3}\right)=30 \times \mathrm{f}_{\text {tall, } \mathrm{w} 3}\left(\mathrm{~d}_{1}\right)$

$\llbracket$ The ostrich is thirty inches taller than the chicken (is) $\rrbracket_{\mathrm{w}}=1$ iff

$\exists \mathrm{r} \in \mathfrak{R}, \mathrm{r}>0, \mathrm{f}_{\text {tall, } \mathrm{w}}\left(\llbracket\right.$ The ostrich $\left.\rrbracket_{\mathrm{w}}\right)-\mathrm{f}_{\text {tall, }, \mathrm{w}}\left(\llbracket\right.$ The chicken $\left.\rrbracket_{\mathrm{w}}\right)=\mathrm{r}=30 \times \mathrm{r}_{i, \mathrm{w}}$ iff $\mathrm{f}_{\text {tall,w }}\left(\mathrm{d}_{2}\right)-\mathrm{f}_{\text {tall,w }}\left(\mathrm{d}_{3}\right)=30 \times \mathrm{f}_{\text {tall,w }}\left(\mathrm{d}_{1}\right)>0$

Let us now focus on short. Interestingly, the degree function of short also adequately represents the fact that the difference between the height of the ostrich and of the chicken equals exactly thirty times the height of an inch unit object. This good result is achieved by virtue of the fact that when degree differences are computed, the transformation values of the two degrees cancel one another, leaving an untransformed value which, as we have just demonstrated, is equal to exactly thirty times the value tall assigns to the inch.

$$
\begin{aligned}
& \text { a. } \mathrm{f}_{\text {short,w1 }}\left(\mathrm{d}_{3}\right)-\mathrm{f}_{\text {short,w1 }}\left(\mathrm{d}_{2}\right)= \\
& \left(\mathrm{w}_{\text {short }, \mathrm{w} 1}-\mathrm{f}_{\text {tall,wl }}\left(\mathrm{d}_{3}\right)\right)-\left(\mathrm{f}_{\text {short }, \mathrm{w} 1}-\mathrm{f}_{\text {tall,w1 }}\left(\mathrm{d}_{2}\right)\right)= \\
& \mathrm{f}_{\text {tall,wl }}\left(\mathrm{d}_{2}\right)-\mathrm{f}_{\text {tall,wl }}\left(\mathrm{d}_{3}\right)=60-30=\mathbf{3 0} \\
& \mathrm{f}_{\text {tall,wl }}\left(\mathrm{d}_{1}\right)=1 \quad \Rightarrow \quad \mathrm{f}_{\text {short,wl }}\left(\mathrm{d}_{2}\right)-\mathrm{f}_{\text {short,wl }}\left(\mathrm{d}_{3}\right)=30 \times \mathrm{f}_{\text {tall,wl }}\left(\mathrm{d}_{1}\right) \\
& \text { b. } \mathrm{f}_{\text {short,w2 }}\left(\mathrm{d}_{3}\right)-\mathrm{f}_{\text {short,w2 } 2}\left(\mathrm{~d}_{2}\right)= \\
& \left(\operatorname{Tran}_{\text {short,w2 } 2}-\mathrm{f}_{\text {tall,w2 }}\left(\mathrm{d}_{3}\right)\right)-\left(\text { Tran }_{\text {short,w2 }}-\mathrm{f}_{\text {tall,w2 }}\left(\mathrm{d}_{2}\right)\right)= \\
& \mathrm{f}_{\text {tall,w2 }}\left(\mathrm{d}_{2}\right)-\mathrm{f}_{\text {tall,w2 }}\left(\mathrm{d}_{3}\right)=120-60=\mathbf{6 0} \\
& \mathrm{f}_{\text {tall,w2 }}\left(\mathrm{d}_{1}\right)=\mathbf{2} \quad \Rightarrow \quad \mathrm{f}_{\text {short,w2 }}\left(\mathrm{d}_{2}\right)-\mathrm{f}_{\text {short,w2 }}\left(\mathrm{d}_{3}\right)=30 \times \mathrm{f}_{\text {tall,w2 }}\left(\mathrm{d}_{1}\right) \\
& \text { c. } \mathrm{f}_{\text {short }, \mathrm{w} 3}\left(\mathrm{~d}_{3}\right)-\mathrm{f}_{\text {short }, \mathrm{w} 3}\left(\mathrm{~d}_{2}\right)= \\
& \left(\operatorname{Tran}_{\text {short,w3 }}-\mathrm{f}_{\text {tall,w3 }}\left(\mathrm{d}_{3}\right)\right)-\left(\operatorname{Tran}_{\text {short,w3 }}-\mathrm{f}_{\text {tall,w3 }}\left(\mathrm{d}_{2}\right)\right)= \\
& \mathrm{f}_{\text {tall,w3 }}\left(\mathrm{d}_{2}\right)-\mathrm{f}_{\text {tall,w3 }}\left(\mathrm{d}_{3}\right)=180-90=\mathbf{9 0} \\
& \mathrm{f}_{\text {tall,w3 }}\left(\mathrm{d}_{1}\right)=\mathbf{3} \quad \Rightarrow \quad \mathrm{f}_{\text {short,w3 }}\left(\mathrm{d}_{2}\right)-\mathrm{f}_{\text {short,w3 }}\left(\mathrm{d}_{3}\right)=30 \times \mathrm{f}_{\text {tall,w3 }}\left(\mathrm{d}_{1}\right)
\end{aligned}
$$

\footnotetext{
${ }^{7}$ The roots of the idea that comparison predicates are non-transformed (the transformation value is set up to zero, so to speak) is already present in Kennedy and McCnally (2005), and Svenonious and Kennedy (2006).
} 
As it holds true in any given world $w$ that the difference between the two degrees short assigns to the chicken and the ostrich equals exactly thirty times the value tall assigns to an inch unit object, the statement The chicken is thirty inches shorter than the ostrich (is) is true in c. ${ }^{8}$

$$
\begin{aligned}
& \llbracket \text { The chicken is thirty inches shorter than the ostrich (is) } \rrbracket_{\mathrm{w}}=1 \quad \text { iff } \\
& \exists \mathrm{r} \in \mathfrak{R}, \mathrm{r}>0, \mathrm{f}_{\text {short }, \mathrm{w}}\left(\llbracket \text { The chicken } \rrbracket_{\mathrm{w}}\right)-\mathrm{f}_{\text {short, } \mathrm{w}}\left(\llbracket \text { The ostrich } \rrbracket_{\mathrm{w}}\right)=\mathrm{r}=30 \times \mathrm{r}_{\mathrm{i}, \mathrm{w}} \\
& \text { iff }\left(\mathrm{f}_{\mathrm{tall}, \mathrm{w}}\left(\llbracket \text { The chicken } \rrbracket_{\mathrm{w}}\right)-\left(\mathrm{f}_{\mathrm{s} \text { tall,w }}(\llbracket \text { The }\right.\right. \\
& \text { ostrich } \left.\rrbracket_{\mathrm{w}}\right)=30 \times \mathrm{r}_{\mathrm{i}, \mathrm{w}} \text { iff } \\
& \mathrm{f}_{\text {tall,w }}\left(\llbracket \text { The ostrich } \rrbracket_{\mathrm{w}}\right)-\mathrm{f}_{\text {tall,w }}\left(\llbracket \text { The chicken } \rrbracket_{\mathrm{w}}\right)=30 \times \mathrm{r}_{\mathrm{i}, \mathrm{w}} \quad \text { iff } \\
& \mathrm{f}_{\text {tall,w }}\left(\mathrm{d}_{2}\right)-\mathrm{f}_{\text {tall,w }}\left(\mathrm{d}_{3}\right)=30 \times \mathrm{f}_{\text {tall,w }}\left(\mathrm{d}_{1}\right)
\end{aligned}
$$

So the present analysis correctly predicts that numerical degree modifiers are felicitous with both positive and negative comparative adjectives.

\subsection{Cross-Polar Anomalies}

How do we account for the fact that, in general, cross-polar comparisons are infelicitous? Consider again the infelicity of *The chicken is taller than the ostrich is short. Here we compute the difference between the degree tall assigns to the chicken and the degree short assigns to the ostrich:

$$
\begin{aligned}
& \llbracket \text { The chicken is taller than the ostrich is short } \rrbracket_{\mathrm{w}}=1 \quad \text { iff } \\
& \mathrm{f}_{\text {tall,w }}\left(\llbracket \text { The chicken } \rrbracket_{\mathrm{w}}-\left(\operatorname{Tran}_{\mathbf{s h o r}, \mathrm{w}}-\mathrm{f}_{\text {tall,w }}\left(\llbracket \text { The ostrich } \rrbracket_{\mathrm{w}}\right)\right)>0 \quad\right. \text { iff } \\
& \mathrm{f}_{\text {tall,w }}\left(\llbracket \text { The chicken } \rrbracket_{\mathrm{w}}+\mathrm{f}_{\text {tall, } \mathrm{w}}\left(\llbracket \text { The ostrich } \rrbracket_{\mathrm{w}}\right)>\operatorname{Tran}_{\mathbf{s h o r}, \mathrm{w}}\right.
\end{aligned}
$$

Since only the degree assigned by short $\left(\operatorname{Tran}_{\mathrm{short}, \mathrm{w}}-\mathrm{f}_{\text {tall, } \mathrm{w}}\left(\llbracket\right.\right.$ The ostrich $\left.\rrbracket_{\mathrm{w}}\right)$ introduces a transformation-value variable, we see that this variable is not canceled out. As its value is unspecified in c, we cannot tell whether the degree difference is a positive number or not (for example, in a world like $\mathrm{w}_{1}$ it is positive, but in a world identical in all to $\mathrm{w}_{1}$, besides the fact that the transformation value equals 100 rather than 10, it is not positive).

$$
\mathrm{f}_{\text {tall,w1 }}\left(\mathrm{d}_{3}\right)-\mathrm{f}_{\text {short,w1 }}\left(\mathrm{d}_{2}\right)=30-\left(\operatorname{Tran}_{\text {short,w1 }}-60\right)=\mathbf{9 0}-\operatorname{Tran}_{\text {short }, \mathrm{w} 1}
$$

In consequence, cross-polar comparisons (such as * The ostrich is taller than the chicken is short) can never be verified or falsified, and are, therefore, considered anomalies. ${ }^{9}$

\subsection{The Zero Test-Intuitions about Transformation Values}

Interestingly, our intuitions concerning the value of entities with, e.g., no height (for instance, surfaces and points) directly reflect the unspecified transformation value of short.

\footnotetext{
${ }^{8}$ Note that in thirty inches shorter, the predicate short does not function as the argument of inches (but as the argument of er), so thirty inches is interpretable (we automatically interpret it as equivalent to thirty inches tall).

${ }^{9}$ For a suggestion of an account of felicitous cross-polar comparisons (e.g., The ladder is $(10 \mathrm{~cm})$ shorter than the house is high) based on the present analysis see Sassoon (2008a).
} 
Additive height-functions, as opposed to transformed ones, must map entities with no height to zero, for otherwise they will not adequately represent height ratios. ${ }^{10}$ We can positively say that an adjective like tall, being linked to conventional additive measuring systems, maps entities with no height to zero. The outcome of measuring entities with no height, such as the surface of the floor, with a ruler (just any possible ruler) is systematically the number zero. ${ }^{11}$

But what about short? If in every world $\mathrm{w}$ of $\mathrm{W}, \mathrm{f}_{\text {tall,w }}$ is additive (it maps entities with no height to 0 ), then short is not transformed (Tran short,w $=0$ in every world $\mathrm{w}$ of $\mathrm{W}_{\mathrm{c}}$ ) iff the degree of entities with no height in short is known to be 0 in c (because in every $\mathrm{w} \in \mathrm{W}_{\mathrm{c}}$ it is $\operatorname{Tran}_{\text {short,w }}-\mathrm{f}_{\text {tall,w }}=0-0=0$ ). But is it? Can we positively say that entities with (almost) no height, such as the surface of the floor, are short to degree (almost) zero? Not really. When I ask speakers to examine their intuitions regarding this issue, they are puzzled. Our intuitions about the point of 'zero shortness', so to speak, are completely blurred. $^{12}$ I propose that this is the natural sign of an unspecified transformation value. It further supports the proposal that the degree function of short is not additive, but a function that transforms height quantities by a

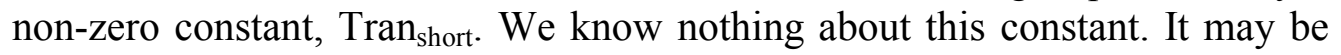
any number (it varies across $\mathrm{W}_{\mathrm{c}}$ ), rendering the zero point undetermined.

\section{6 'Exceptional' Adjective Types}

Until now, I have shown that the present analysis correctly captures the main generalizations pertaining to contrasts between positive and negative adjectives. We can now proceed to explain exceptions to these generalizations.

The present proposal clearly distinguishes between function-reversal (namely the use of functions that are linearly reversed in comparison with the base function, as explained in Section 2.4) and linear-transformation (namely, the displacement of the zero compared to the base function, as explained in 2.4). This means that we can distinguish between four groups of functions:
a. Non-Reversed and Non-Transformed (e.g., $\left.\lambda \mathrm{d} \in \mathrm{D} .0+\mathrm{f}_{\text {tall,w1 }}(\mathrm{d})\right)$
b. Reversed and Transformed (e.g., $\left.\lambda d \in D .1-f_{\text {tall,w1 }}(d)\right)$
c. Non-Reversed and Transformed (e.g., $\left.\lambda d \in D .1+f_{\text {tall,wl }}(d)\right)$
d. Reversed and Non-Transformed (e.g., $\lambda \mathrm{d} \in \mathrm{D} .0-\mathrm{f}_{\text {tall,wl }}(\mathrm{d})$ )

\footnotetext{
${ }^{10}$ In order to see this consider, for example, a function $\mathrm{f}$, such that $\mathrm{f}$ maps some entity $\mathrm{d}_{0}$ with no height (say, the surface of the floor) to some number other than zero, say, $1 / 2$ and $\mathrm{f}$ maps a meter unit-object to the number 1 . The ratio between $d_{0}$ 's value and the value of a meter unit-object is then the non-zero number $1 / 2$ (it is half a meter tall), while the ratio between $\mathrm{d}_{0}$ 's height and the height of a meter unit-object (or any other object) is 0 . Thus, $\mathrm{f}$ does not adequately represent height ratios.

${ }^{11}$ Speakers who feel that entities with no height fall outside the domain of the degree function of tall and short can examine their intuitions about entities with almost no height, which tall maps to a degree that approximates zero (or to a very small degree compared to the degrees of entities with notable amounts of height).

${ }^{12}$ Some semantic theories (von Stechow 1984, Kennedy 1999) endorse the view that entities with (almost) no height are mapped to (a degree that approximates) infinity (formally, they are mapped to the largest interval $(0, \propto)$, not the zero interval $(0,0))$. Therefore, in these theories, too, the degree function of short transforms height quantities by a non-zero constant. In fact, given that entities with almost no height are very short, it is strange to think of them as short to a degree which is very small (compared to other entities).
} 
I propose that, on one hand, the degree functions associated with (the default interpretations of) positive adjectives may be based on additive measuring conventions. On the other hand, the degree functions of negative adjectives are not based directly on a given measuring convention, but on function reversal. As a consequence of the lack of a completely specified convention or rule of reversal, by default, negative adjectives are transformed by an unspecified value. It is easy to see that this proposal predicts that the functions of many positive and negative adjectives would pattern with the function-types (33a) and (33b), respectively.

In addition, some positive adjectives may pattern with (33c). Nothing in my proposal prevents positive adjectives from being transformed. Thus, the present analysis (unlike any of its predecessors) captures properties of exceptional positive adjectives, like warm. The degrees of positive adjectives are not reversed, but they may well be transformed. This explains the infelicity of 2 degrees warm (as opposed to the felicity of two degrees warmer). ${ }^{13}$

The present analysis also captures our unclear intuitions concerning the zero point of warm, as a temperature adjective (namely, when interpreted as mapping objects to their temperature as measured by a thermometer). Why is it that the zero of this interpretation of warm is transformed? Entities that scientists claim possess no heat are mapped to zero on the Kelvin scale. They are not mapped to zero Celsius, though! The Celsius scale is a transformed scale, which is defined according to the Kelvin scale. ${ }^{14}$ In particular, entities with no heat are mapped to -273 Celsius degrees. We do not often encounter or discuss events or entities with this temperature. We actually sense entities to be without heat long before they reach -273 degrees Celsius. So our scale of temperature perception does not correspond to external temperature measures, in that its zero is transformed. The existence of a transformed unitname like Celsius further supports the view that warm as a temperature adjective may also be associated with transformed measures.

Languages may vary as to whether the degree functions of adjectives like heavy or warm (as measuring external weight or temperature, respectively) are transformed (whether they are affected by our perception of weight or of temperature, respectively). Thereby, languages may differ as to whether ratio modifiers are licensed and whether numerical degree modifiers are licensed in non-comparative forms.

In contrast, given my proposal, for lack of a completely specified rule of reversal, by default, negative adjectives are expected to be transformed by an unspecified value, i.e. not to pattern with (33d), except in exceptional adhoc uses. ${ }^{15}$ Whether there are counterexamples is a question for future research (see Sassoon 2008a for a detailed discussion). ${ }^{16}$

\footnotetext{
${ }^{13}$ In previous theories, degrees of positive adjectives, including warm, are initial intervals and degrees of negative adjectives are final intervals (e.g., von Stechow 1984, Kennedy 1999, 2001, Schwarzschild 2005), so it is incorrectly predicted that only the latter do not combine with numerical degree modifiers.

${ }^{14}$ See a discussion of related linguistic facts and their account in Sassoon 2007, 2008b.

${ }^{15}$ For example, consider a situation in which the length of different short stories is measured based on the number of words in each story. In this situation, we may utter and accept as felicitous ratio statements like This story is twice as short as that one. In the given situation, short's degree function is indeed locally based on an ad-hoc measuring-convention (number of words). So short is reversed, but not transformed. This 'additive' convention-based interpretation is definitely not the dominant or default interpretation of short, as indicated by
} 


\section{Conclusions}

We have presented compelling arguments in favor of the new proposal. It yields a simple and fruitful explanation of the main differences between positive and negative adjectives, and of additional facts pertaining to the licensing of numerical degree modifiers. At the same time, it is simpler than previous theories in that degrees are numbers, not intervals.

\section{References}

Bierwisch, M.: 1989, 'The Semantics of Gradation', Manfred Bierwisch and Ewald Lang (eds.) Dimensional Adjectives: Grammatical Structure and Conceptual Interpretation, Springer-Verlag, Berlin, 71-261.

Brasoveanu, Adrian: 2008, 'Measure Noun Polisemy and Monotonicity: Evidence from Romanian Pseudopartitives', Proceedings of the 38th Meeting of the North East Linguistic Society.

Büring, Daniel: 2007, 'Cross-Polar Nomalies', Proceedings of Semantics and Linguistic Theory XVII, CLC publications, University of Connecticut.

Chierchia, Gennaro: 1998, 'Plurality of Mass Nouns and The Notion of Semantic Parameter', in Susan Rothstein (ed.) Events and Grammar, Kluwer, 53-103.

Heim, Irene: 2000, 'Degree operators and scope', Proceedings of SALT X, CLC Publications, Ithaca, NY.

Heim, Irene: 2006, 'Remarks on comparative clauses as generalized quantifiers', Manuscript, MIT.

Heim, Irene: 2008, 'Decomposing Antonyms?', Proceedings of SUB14.

Horn, Laurence: 1972, 'On the semantic properties of logical operators in English.' Unpublished Doctoral dissertation, Uni. of California, Los Angeles.

Kadmon, Nirit: 1987, On unique and Non-unique Reference and Asymmetric quantification, Doctoral dissertation, Uni. of Massachusetts, Amherst. Reproduced by the GSLA linguistic department, Uni. of Massachusetts, Amherst. Also published by Garland Press 1992.

Kennedy, Christopher (1999), Projecting the adjective: The Syntax and Semantics of Gradability and Comparison. Garland. NY. (1997 UCSC Doctoral dissertation).

Kennedy, Christopher: 2001, 'Polar opposition and the ontology of degrees', Linguistics and Philosophy 24(1), 33-70.

Kennedy, Christopher and Beth Levin: 2008, 'Measure of Change: The Adjectival Core of Degree Achievements', in McNally, Louise and Christopher Kennedy (eds.) Adjectives and Adverbs: Syntax, Semantics and Discourse, Oxford University Press.

Kennedy, Christopher and McNally, Louise: 2005, 'Scale structure and. the semantic typology of gradable predicates', Language 81, 345-381.

the fact that the number of Google results of the form "twice as short as" (934) is drastically smaller than the number of results of the form "twice as long as" $(323,000)$.

${ }^{16}$ Sassoon (2008a) argues that in the few antonym pairs in which the negative adjective occurs more often with ratio modifiers than the positive counterpart, this is due to the fact that the positive adjective is transformed, not due to the negative adjective not being transformed. 
Klein, Ewan: 1991, 'Comparatives', in: Arnim von Stechow and Dieter Wunderlich (eds.) Semantik / Semantics, An International Handbook of Contemporary Research, Berlin, New York: Walter de Gruyter, 673691.

Krantz, David H.; Luce, R. Duncan; Suppes, Patrick, and Tversky, Amos: 1971, Foundations of measurement: Additive and Polynomial Representations, Academic Press, Uni. of Fribourg, San Diego, London.

Krifka, Manfred: 1989, 'Nominal Reference, Temporal Constitution and Quantification in Event Semantics', in Bartsch, R., van Benthem, J,. van Emde Boas, P. (eds.) Semantics and Contextual Expressions, Foris, Dordrecht, 75-115.

Landman, Fred: 2005, 'An almost (but not quite) naïve theory of measures', Manuscript, Tel Aviv university.

Mcconnell-Ginet, Sally: 1973, Comparative Constructions in English: A Syntactic and Semantic Analysis, Doctoral dissertation, Uni. of Rochester.

Moltmann, Friederike: 2006, 'Comparatives without Degrees, A New Approach', A manuscript for the workshop on scalar meaning, Uni. of Chicago.

Rullmann, Hotze: 1995, Maximality in the Semantics of WH-Constructions. Doctoral dissertation, University of Massachusetts, Amherst.

Sassoon, W. Galit: 2007, Vagueness, Gradability and Typicality, A Comprehensive semantic analysis. Unpublished Doctoral Dissertation, Tel Aviv University.

Sassoon, W. Galit: 2008a (in progress), 'The degree functions of Negative Adjectives', Manuscript.

Sassoon, W. Galit: 2008b (in progress), 'Vagueness pertaining to numerical degree constructions', Manuscript based on a presentation in "Vagueness and Language use", Paris.

Schwarzschild, Roger: 2005, 'Measure phrases as modifiers of adjectives', Recherches Linguistiques de Vincennes 35, 207-228.

Schwarzschild, Roger (2006), The Role of Dimensions in the Syntax of Noun Phrases Syntax 9.1, 67-110.

Schwarzschild, Roger, and Karina Wilkinson: 2002, 'Quantifiers in Comparatives: A Semantics of Degree Based on Intervals', Natural Language Semantics 10, 1-41.

Stalnaker, Robert: 1978, 'Assertion', in Peter Cole (ed.) Syntax and Semantics 9: Pragmatics, Academic Press, 315-332.

Svenonious, Peter and Christopher Kennedy: 2006, 'Northern Norwegian degree questions and the syntax of measurement', Mara Frascarelli (ed.) Phases of Interpretation, The Hague. Muton de Gruyter, 133-161.

von Stechow, Arnim: 1984a, 'My Reaction to Cresswell's, Hellan's, Hoeksema's and Seuren's Comments', Journal of Semantics 3, 183199.

von Stechow, Arnim: 1984b, 'Comparing Semantic Theories of Comparison', Journal of Semantics 3, 1-77. 